\title{
Unsteady Mixed Convection Flow in the Stagnation Region of a Heated Vertical Plate Embedded in a Variable Porosity Medium with Thermal Dispersion Effects
}

\author{
S. M. Alharbi ${ }^{1}$ and I. A. Hassanien ${ }^{2}$ \\ ${ }^{1}$ Department of Mathematics, Faculty of Science, \\ Umm AL-Qura University, P.O. 8140, KSA \\ ${ }^{2}$ Department of Mathematics, Faculty of science, Assiut University, Assiut,
}

Egypt

\section{Introduction}

The mixed convection flow finds applications in several industrial and technical processes such as nuclear reactors cooled during emergency shutdown, solar central receivers exposed to winds, electronic devices cooled by fans and heat exchanges placed in a low-velocity environment. The mixed convection flow becomes important when the buoyancy forces increase due to the temperature difference between the wall and the free stream. The mixed convection flow in the stagnation region of a vertical plate has been investigated by Ramachandra et al. [16].

When there is an impulsive change in the velocity field the inviscid flow is developed instantaneously, but the flow in the viscous layer near the wall is developed slowly which becomes fully developed steady flow after a while. For small period the flow is dominated by the viscous forces and the unsteady acceleration, but for runtime it is dominated by the viscous forces, the pressure gradient and the convective acceleration. The unsteady mixed convection flow in the stagnation region of a heated vertical plate due to impulsive motion has been studied by Schadri et al. [17]. The boundary layer flow development of a viscous fluid on a semi-infinite flat plate due to impulsive motion of the free stream have been investigated by Hall [5], Dennis [3] and Watkins [22]. The corresponding problem over a wedge has been studied by Simth [18], Nanbu [11] and Williams \& Rhyne [23].

The problem of unsteady free convection flow in the stagnation-point region of a rotating sphere embedded in a porous medium has been analyzed by Hassanien et al. [7]. The unsteady flow and heat transfer of a viscous fluid in the stagnation region of a threedimensional body embedded in a porous medium was investigated by Hassanien et al. [8]. The problem of thermal radiation and variable viscosity effects on unsteady mixed convection flow in the stagnation region on a vertical surface embedded in a porous medium with surface heat flux has been studied by Al-Arabi and Hassanien [6].

Motivated by all of the above referenced work and the significant possible applications of porous media in industries, it is of interest in this paper to consider the unsteady mixed convection flow in the region of a heated vertical plate embedded in a porous medium 
having porosity distribution in the presence of the thermal dispersion with the effect of the buoyancy force. The unsteadiness in the flow field is caused by impulsively creating motion in the free stream and at the same time by suddenly increase in the surface temperature. The partial differential equations governing the flow and the heat transfer have been solved numerically using the finite difference scheme by Pereyra [14]. Particular cases of the present results are compared with previously numerical work by Ramachandra et al. [16] and Scshadri et al. [17]. The problem is formulated in such way that it represented by Rayleigh type of equation at $\mathrm{t}=0$ and for $t \rightarrow \infty$ it represented by type of Hemennz equation.

\section{Mathematical analysis}

Let us consider a semi-infinite vertical plate embedded in a variable porosity porous medium with thermal dispersion effect and uniform temperature $\mathrm{T}_{\infty}$. At $t=0.0$ the ambient fluid is impulsively moved with a velocity $U_{e}$ and at the same time the surface temperature is suddenly raised. Figure (1) shows a flow field over a heated vertical surface where the upper half of the field is assisted by the buoyancy force, but the lower part is opposed by the buoyancy force. The surface of the plate is assumed to have an arbitrary temperature. All the physical properties of the fluid are assumed to be constant except the density variation in the buoyancy force term. Both the fluid and the porous medium are assumed to be in local thermal equilibrium. Under above assumptions along with Boussinesq approximation, the unsteady laminar boundary layer equations governing the mixed convection flow are given by Vafai and Tien [20].

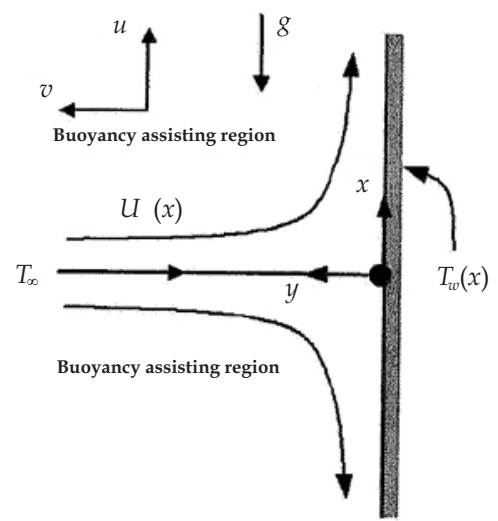

Fig. 1. The flow model and the coordinate system

$$
\begin{gathered}
\frac{\partial u}{\partial x}+\frac{\partial v}{\partial y}=0 \\
\frac{1}{\varepsilon} \frac{\partial u}{\partial t}+\frac{1}{\varepsilon^{2}}\left(u \frac{\partial u}{\partial x}+v \frac{\partial u}{\partial y}\right)=U_{e} \frac{\partial U_{e}}{\partial x}+\frac{v}{\varepsilon} \frac{\partial^{2} u}{\partial y^{2}}+g \beta\left(T-T_{\infty}\right)+\frac{v}{k(y)}\left(u_{e}-U_{e}\right) \\
\frac{\partial T}{\partial t}+u \frac{\partial T}{\partial x}+v \frac{\partial T}{\partial y}=\frac{\partial}{\partial y}\left(\alpha_{c} \frac{\partial T}{\partial y}\right)
\end{gathered}
$$


The initial conditions are given by

$$
u(x, y)=v(x, y)=0, \quad T(x, y)=T_{\infty}, \text { for } t<0 .
$$

The boundary conditions for $t \geq 0$ are given by

$$
\begin{aligned}
& u(x, 0)=v(x, 0)=0, \quad u(x, \infty)=U_{e}=a x, \quad a>0, \\
& T(x, \infty)=T_{\infty}, T(x, 0)=T_{w}(x)=b x^{n}, \quad b>0, \quad n \geq 0 .
\end{aligned}
$$

The indices $n=0$ and $n=1.0$ correspond the constant surface temperature and the linear surface temperature respectively. The variable $x$ is measured along the surface and $y$ is measured normal to it. The fluid velocity $\mathrm{u}, \mathrm{v}$ is in $\mathrm{x}$ and $\mathrm{y}$ direction respectively as shown in figure (1). The fluid density, the fluid dynamical viscosity, the gravitational fluid acceleration, the thermal expansion coefficient and the temperature will be denoted by $\rho, \mu, g, \beta, T$ respectively. $\mathrm{K}(\mathrm{y})$ is the porous medium permeability, $\alpha_{c}$ is the effective thermal diffusivity and $\varepsilon$ is the porous medium porosity. Equations (1) through (3) are supplemented by constitutive equations for the variations of the porosity permeability and thermal conductivity of the porous medium. It has been shown by Vafai [21] that the results obtained experimentally by Nithiarasu et al. [12 ] in their study on void fraction distribution in packed beds gives the functional dependence of the porosity on the normal distance from the boundary and so the porosity can be represented by the exponential form

$$
\varepsilon=\varepsilon_{0}(1+b \exp (-c y / d))
$$

where $\varepsilon_{0}$ is the free-stream porosity, $\mathrm{d}$ is the particle diameter and $\mathrm{b}, \mathrm{c}$ are empirical constants that depend on the ratio of the bed to particle diameter. The values for $\varepsilon_{0}, \mathrm{~b}$ and $\mathrm{c}$ chosen to be $0.38,1$, and 2 respectively. These values were found to give good approximation to the variable porosity data given by Nithiarasu et al. [12] for a particle diameter $\mathrm{d}=5 \mathrm{~mm}$. The type of decay of porosity as the normal distance increases given by Equation (4) is well established and has been used extensively in studies on flow in porous media with variable porosity. It is also established that $\mathrm{k}(\mathrm{y})$ varies with the porosity as follows

$$
K(y)=\frac{d^{2} \varepsilon^{3}}{150(1-\varepsilon)^{2}}
$$

The effective thermal conductivity of the porous medium is given by Al-Arabi and Hassanien [6]

$$
\alpha_{c}=\alpha_{m}+\gamma \mathrm{d}|u|
$$

where $\alpha_{m}$ and $\gamma$ are the molecular thermal diffusivity and mechanical dispersion coefficients, respectively. Equations (1) through (3) can be transformed into a set of ordinary differential equations by using the following transformations given by Williams and Rhyne [23].

$$
\begin{gathered}
\eta=(a / v)^{1 / 2} y \xi^{-1 / 2}, \quad \xi=1-\exp \left(-t^{*}\right), \\
t^{*}=a t, \quad a>0, \quad u(x, y, t)=a x f^{\prime}(\eta, \xi), \\
v(x, y, t)=-(a v)^{1 / 2} \xi^{1 / 2} f(\eta, \xi),
\end{gathered}
$$




$$
\begin{gathered}
T(x, y, t)=T_{\infty}+\left(T_{w}(x)-T_{\infty}\right) \theta(\eta, \xi), \\
\operatorname{Pr}=v / \alpha, \quad \lambda=G r_{x} / \operatorname{Re}_{x}^{2}, \\
G r_{x}=g \beta\left(T-T_{\infty}\right) x^{3} / v^{2}, \quad \operatorname{Re}_{x}=a x^{2} / v .
\end{gathered}
$$

By using the transformations (9), equations (2-5) may be transformed to

$$
\begin{aligned}
& f^{\prime \prime \prime}+2^{-1} \eta(1-\xi) f^{\prime \prime}+\frac{\xi}{\varepsilon} f f^{\prime \prime}+\frac{\xi}{\varepsilon}\left(1-f^{\prime 2}\right)-D a^{2} \frac{150(1-\varepsilon)^{2}}{\varepsilon}\left(1-f^{\prime}\right) \\
& -\frac{\xi}{\varepsilon}\left(1-f^{\prime 2}\right)+\lambda \xi \varepsilon \theta=\varepsilon \xi(1-\xi) \frac{\partial f}{\partial \xi} \\
& \operatorname{Pr}^{-1} \theta^{\prime \prime}++D s\left(f^{\prime} \theta^{\prime}\right)^{\prime}+2^{-1} \eta(1-\xi) \theta^{\prime}+\xi\left(f \theta^{\prime}-n f^{\prime} \theta\right)=\xi(1-\xi) \frac{\partial \theta^{\prime}}{\partial \xi}
\end{aligned}
$$

where $D a=\frac{v}{a d^{2}}$ is the Darcian parameter, $D s=\frac{\gamma d}{a}$ is the dispersion parameter, $\lambda>0$ for the buoyancy assisting flow and $\lambda<0$ for the buoyancy opposing flow. The transformed form of the variable porosity function becomes

$$
\varepsilon=\varepsilon_{0}(1+b \exp (-c \eta \sqrt{\xi} D a))
$$

The boundary conditions (5) may be reduce to

$$
\begin{array}{lr}
f(0, \xi)=f^{\prime}(0, \xi)=0, & f^{\prime}(\infty, \xi)=1.0, \\
\theta(\infty, \xi)=0, & \theta(0, \xi)=1.0 .
\end{array}
$$

It may be noted that the buoyancy parameter $\lambda$ is a function of streetwise distance $x$ unless the surface temperature $\left(T_{w}=T_{\infty}\right)$ for $n=1.0, \lambda$ is constant. Equations (10) and (11) are coupled nonlinear partial differential equations, but for $\xi=0,\left(t^{*}=0\right)$ and $\xi=1.0,\left(t^{*} \rightarrow \infty\right)$ and they can be reduced to ordinary differential equations. For the case $\xi=0.0$, these equations take the form

$$
\begin{gathered}
f^{\prime \prime \prime}+2^{-1} \eta f^{\prime \prime}=0, \\
\theta^{\prime \prime}+2^{-1} \operatorname{Pr} \eta \theta^{\prime}=0 .
\end{gathered}
$$

For the case $\xi=1$, equations (7), (8) can be reduced to

$$
\begin{gathered}
f^{\prime \prime \prime}+f f^{\prime \prime}+\left(1-f^{\prime 2}\right)-\gamma\left(1-f^{\prime}\right)-\Delta\left(1-f^{\prime 2}\right)+\lambda \theta=0, \\
\operatorname{Pr}^{-1} \theta^{\prime \prime}+\left(f \theta^{\prime}-n f^{\prime} \theta\right)=0 .
\end{gathered}
$$

For the above two special cases the boundary conditions (5) may be reduce to

$$
\begin{array}{lr}
f(0)=f^{\prime}(0)=0, & f^{\prime}(\infty)=1.0, \\
\theta(\infty)=0, & \theta(0)=1.0
\end{array}
$$


Equations (13), (14) are uncoupled linear equations while equations (15), (16) are coupled nonlinear equations. Equations (13) and (14) under conditions (17) admit closed form solutions which are given by,

$$
\begin{gathered}
f=\eta \operatorname{erfc}(\eta / 2)-(\pi)^{1 / 2}\left[1-\exp \left(-\eta^{2} / 4\right)\right], \\
\theta=\operatorname{erfc}\left(\operatorname{Pr}^{1 / 2} \eta / 2\right)
\end{gathered}
$$

hence we have

$$
f^{\prime \prime}(0)=(\pi)^{1 / 2}, \quad \theta^{\prime}(0)=-(\operatorname{Pr} / \pi)^{1 / 2} .
$$

Equations (15), (16) do not admit closed form solutions. Equations (10), (11) under conditions (12) for $\xi=1$ (steady case) and non porous media are identical to those of Ramachandra et al. [16] in nonporous medium $(\varepsilon=1$. Also equations (10-11) under the condition $\lambda=0$ (forced convection flow) and $\varepsilon=1$ are the same as that of Williams and Rhyne [23] if we put $\mathrm{m}=1$ in their equation. The physical quantities of interest in this problem are the skin friction coefficient and the Nusselt number, which are defined by Pop et al. [15].

$$
C_{f}=2 \tau_{w} / \rho U_{\infty}^{2}, \quad N u=x q_{w} / \alpha\left(T_{w}-T_{\infty}\right),
$$

where $\tau_{w}=\mu(\partial u / \partial y)_{y=0}$ and $q_{w}=-\alpha(\partial T / \partial y)_{y=0}$. Using equations (9), the quantities in Eqs. (21) can be expressed in the form

$$
\begin{gathered}
C_{f}=2 \xi^{-1 / 2} \operatorname{Re}_{x}^{-1 / 2} f^{\prime \prime}(\xi, 0), \quad \xi>0 . \\
N u=-\operatorname{Re}_{x}^{1 / 2} \xi^{-1 / 2} \theta^{\prime \prime}(\xi, 0), \quad \xi>0 .
\end{gathered}
$$

\section{Method of solution}

We are going now discuss the local non-similarity method to solve equations (10), (11). Since it was already seen by Pereyra [14], and Sparrow et al. [19] that for the problem of coupled local non-similarity equations, the considerations of equation up to the second level of truncation gives almost accurate results comparable with the solutions from other methods. We will consider here the local non-similar equations (10), (11) only up to the second level of truncation. To do this, we introduce the following new functions

$$
g=\partial f / \partial \xi, \quad \phi=\partial \theta / \partial \xi
$$

Introducing these functions into equations (10) and (11) we get

$$
\begin{gathered}
f^{\prime \prime \prime}+2^{-1} \eta(1-\xi) f^{\prime \prime}+\frac{\xi}{\varepsilon} f f^{\prime \prime}+\frac{150(1-\varepsilon)^{2}}{\varepsilon^{2}} D a^{2}\left(1-f^{\prime}\right)+\frac{\xi}{\varepsilon}\left(1-f^{\prime 2}\right)+\lambda \xi \varepsilon \theta=\varepsilon \xi(1-\xi) g \\
\operatorname{Pr}^{-1} \theta^{\prime \prime}++D s\left(f^{\prime} \theta^{\prime}\right)^{\prime}+2^{-1} \eta(1-\xi) \theta^{\prime}+\xi\left(f \theta^{\prime}-n f^{\prime} \theta\right)=\xi(1-\xi) \phi^{\prime}
\end{gathered}
$$

Differentiating the above equations with respect to $\xi$ one may easily neglect the terms involving the derivative functions of $g$ and $\phi$ with respect to $\xi$ as follows 


$$
\begin{aligned}
& g^{\prime \prime \prime}+2^{-1} \gamma\left[(1-\xi) g^{\prime \prime}-f^{\prime \prime}\right]+\frac{\varepsilon}{\varepsilon^{2}}\left[\varepsilon f g^{\prime \prime}+\varepsilon g f^{\prime \prime}+f f^{\prime \prime}-\frac{\varepsilon f f^{\prime \prime} \varepsilon_{\xi}}{\varepsilon}\right]+ \\
& \frac{\varepsilon}{\varepsilon^{2}}\left[\left(1-f^{\prime 2}+\varepsilon\left(-2 f^{\prime} g\right)-\frac{\left(1-f^{\prime 2}\right) \varepsilon_{\xi}}{\varepsilon}\right]+\right. \\
& 150 D a^{2} \frac{1}{\varepsilon^{2}}\left[\left(1-\varepsilon^{2}\right)^{2}\left(-g^{\prime}\right)+\left(1-f^{\prime}\right)\left\{(2)(1-\varepsilon)\left(-\varepsilon_{\xi}\right)-2 \frac{(1-\varepsilon)^{2} \varepsilon_{\xi}}{\varepsilon}\right\}\right] \\
& -\frac{1}{\varepsilon}\left[\left(1-f^{\prime 2}\right)+\xi 2 f^{\prime} g^{\prime}-\xi \frac{(1-f) \varepsilon_{\xi}}{\varepsilon}\right]+\lambda \varepsilon \xi \phi+\lambda \theta \varepsilon+\lambda \xi \theta \varepsilon_{\xi}=\varepsilon \phi(1-2 \xi)+\xi(1-\xi) \varepsilon_{\xi} \phi \\
& p r^{-1} \phi^{\prime \prime}+p s\left(g^{\prime} \theta^{\prime \prime}+\theta^{\prime} g^{\prime \prime}\right)+2^{-1} \gamma(1-\xi) \phi^{\prime} \\
& -2^{-1} \gamma \theta^{\prime}+\left(f \theta^{\prime}-n f^{\prime} \theta\right)+\xi\left(f \phi^{\prime}+g \theta^{\prime}-n g^{\prime} \theta-n f^{\prime} \phi\right) \\
& =(1-2 \xi) \phi^{\prime}
\end{aligned}
$$

where $\varepsilon_{\xi}$ is the derivative of $\varepsilon$ with respect to $\xi$. The appropriate boundary conditions satisfied by the above equations are given by

$$
\begin{array}{cr}
f(0, \xi)=f^{\prime}(0, \xi)=0, & f^{\prime}(\infty, \xi)=1.0, \\
\theta(\infty, \xi)=0, & \theta(0, \xi)=1.0 . \\
g(0, \xi)=g^{\prime}(0, \xi)=\phi(0, \xi)=0, \\
g^{\prime}(\infty, \xi)=\phi(\infty, \xi)=0 .
\end{array}
$$

\section{Results and discussion}

In order to validate our numerical solutions, we have compared the surface shear stress $f^{\prime \prime}(\xi, 0)$ and the surface heat transfer $-\theta^{\prime}(\xi, 0)$ for the prescribed surface temperature with those of Ramachandra et al. [16] and Scshadri et al. [17]. The results are found to be almost compatible to a reasonable degree.. The comparison is shown in Figures (2) and (3), which corresponding Figures (2) and (3) in Scshadri [17].

The variation of the surface shear stress $f^{\prime \prime}(\xi, 0)$, the surface heat transfer rate $-\theta^{\prime}(\xi, 0)$ with time $\xi(0 \leq \xi \leq 1)$ for the Darcy parameter $D a$, the dispersion parameter $D s$ in the presence of the buoyancy assisting flow $(\lambda=1)$ and buoyancy opposing flow $(\lambda=-1)$ for the non-isothermal surface $(n=1)$ are shown in Figures (2) through (6).

At the start of motion $(\xi=0)$, the buoyancy force parameter $(\lambda)$, the Darcy parameter $D a$ and the dispersion parameter $D s$ have no effects on both the surface shear stress and the surface heat transfer and these effects become pronounced with increasing time $\xi$. The steady state is reached at $\xi=1\left(t^{*} \rightarrow \infty\right)$. The surface shear stress $f^{\prime \prime}(\xi, 0)$ and surface heat transfer $-\theta^{\prime}(\xi, 0)$ decrease with the Darcy and dispersion parameters increasing for the two cases (the buoyancy assisting flow $(\lambda=1)$ and the buoyancy opposing flow $(\lambda=-1))$. It is also clear from these figures that the surface shear stress and heat transfer for buoyancy assisting flow are greater than those of the buoyancy opposing flow. Also, the surface shear stress and the heat transfer rate increase with increasing the Darcy parameter Da and the dispersion parameter Ds. 


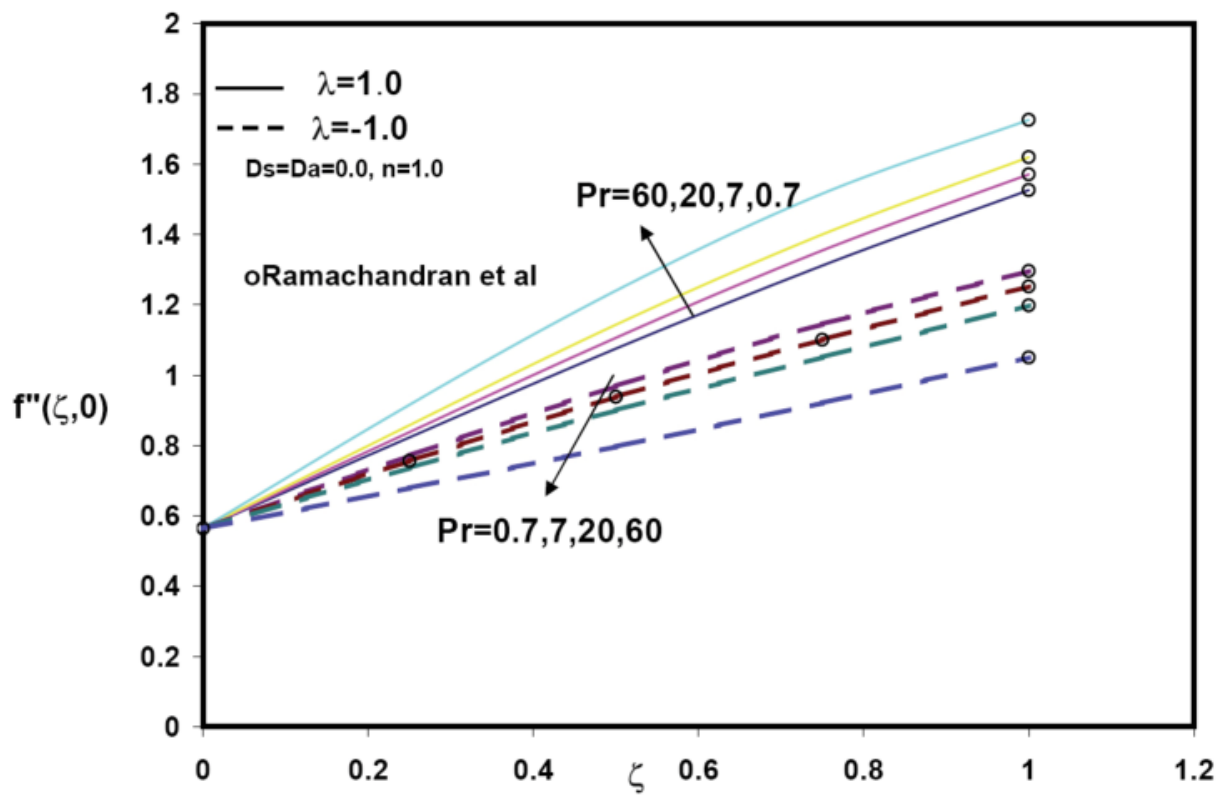

Fig. 2. Variation of shear stress $f^{\prime \prime}(\xi, 0)$ with time $\xi$

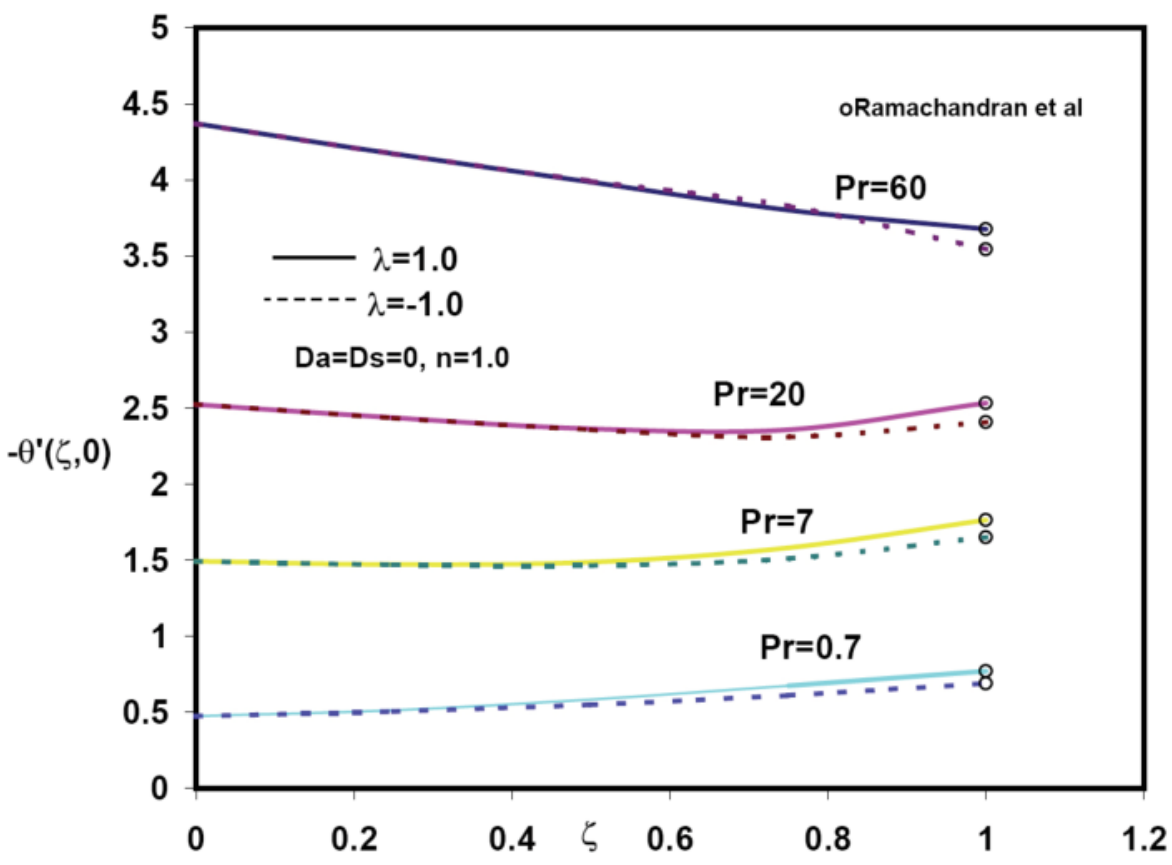

Fig. 3. Variation of surface heat transfer $\theta^{\prime}(\xi, 0)$ with time $\xi$ 


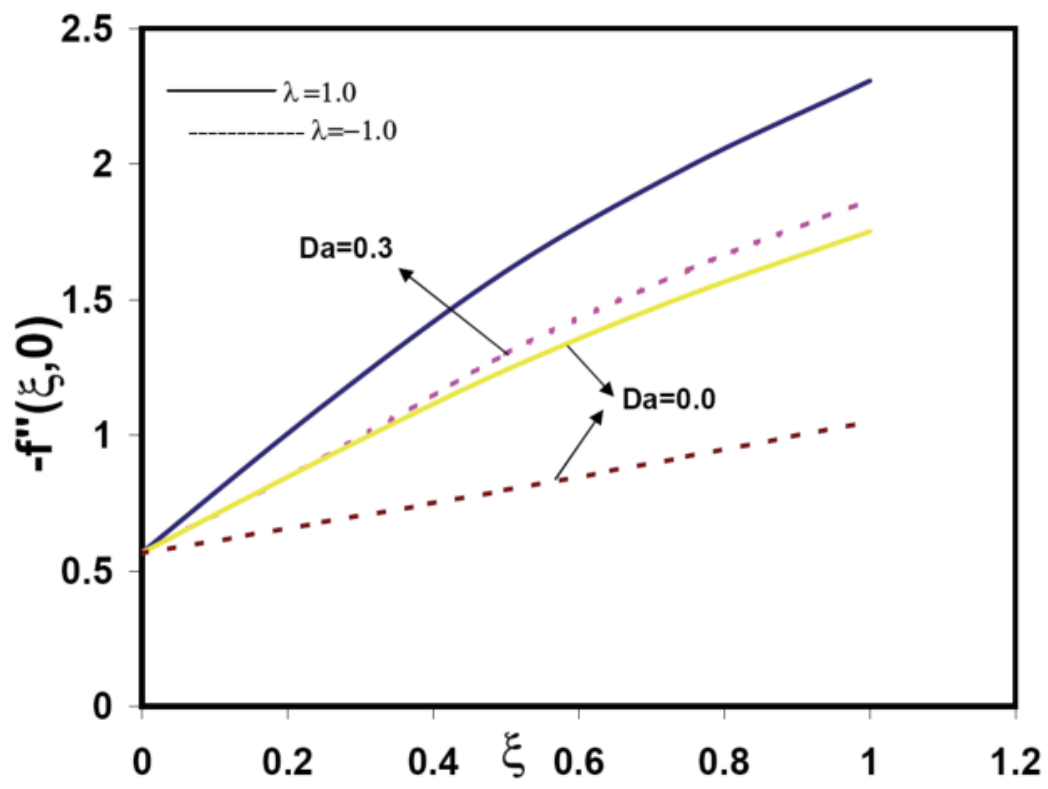

Fig. 4. Variation of surface shear stress with time for $\varepsilon_{0}=0.38, b=1.0, c=2.0, D s=0.0$ and Pr=0.7

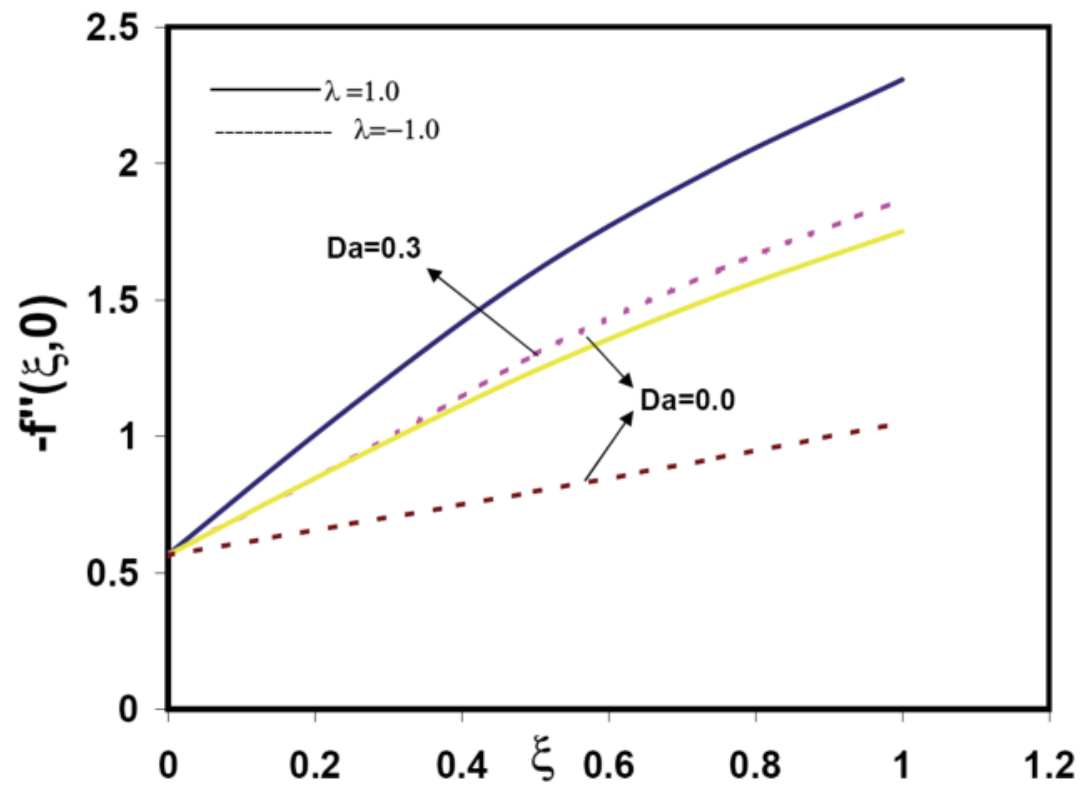

Fig. 5. Variation of the surface heat transfer rate $\theta^{`}(\xi, 0)$ with time $\xi$ for $\varepsilon_{0}=0.38, b=1.0$, $c=2.0, d=5.0, D s=0.0$ and $\operatorname{Pr}=0.7$ 


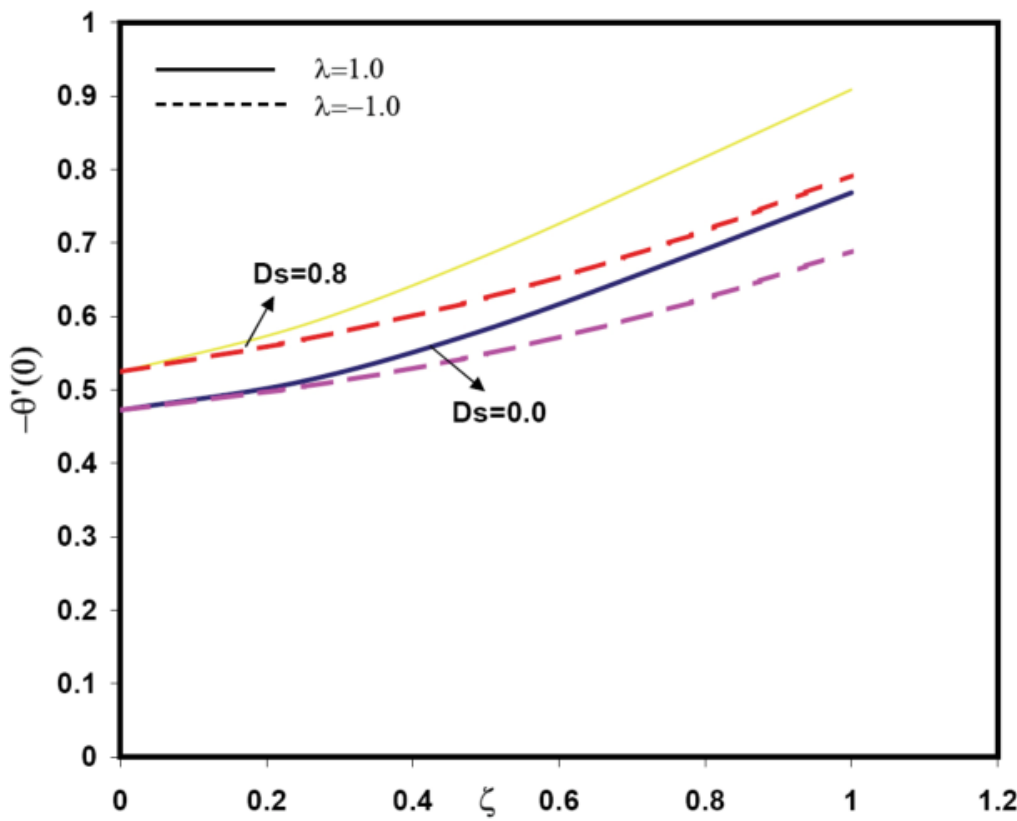

Fig. 6. Variation of the surface heat transfer rate $\theta^{`}(\xi, 0)$ with time $\xi$ for $\varepsilon_{0}=0.38, b=1.0$, $c=2.0, d=5.0, D s=0.0$ and $\operatorname{Pr}=0.7$

Figures (5), (6) display the variation of the surface shear stress and the surface heat transfer with time $\xi$ for the prescribed surface temperature when the buoyancy parameter $\lambda=1.0,-1.0, p r=0.7, n=-0.5$ and for the Darcy parameter $\mathrm{Da}=0.0,0.3$, and the dispersion parameter Ds $=0.0,0.8$. The surface shear stress and the heat transfer increase with $\lambda$ because positive buoyancy force acts like favorable pressure gradient which accelerates the motion and reduces both momentum and thermal boundary layers. Hence both the surface shear stress and the surface heat transfer are increased.

\section{Acknowledgement}

This research has been supported by a grant from the Institute of Scientific Research at Umm Al-Qura University, Saudi Arabia.

\section{References}

[1] Amin N. and Riley N., (1995), "Mixed convection at a stagnation point", Quart. J. Mech. App. Maths. Vol. 48, pp. 111-121.

[2] Brown S. N. and Riley N, (1973), "Flow past a suddenly heated vertical plate", J. Fluid Mech. Vol. 59, pp. 225-237.

[3] Dennis S. C. R., (1972), "The motion of a viscous fluid past an impulsively started semiinfinite flat plate", IMA J. Appl. Math. Vol. 10, pp. 105-117.

[4] Ece M. C., (1992), "An initial boundary layer flow past a translating and spinning rotational symmetric body", J. Eng. Math. Vol. 26, pp. 415-428. 
[5] Hall M. G., (1969), "The boundary layer over an impulsively started flat plate", Proceedings of the Royal Society of London, Series A, Mathematical and physical science, Vol. 310A, pp. 401-414.

[6] Hassanien, I.A. and Al-Arabi, T.H., (2008), "Thermal Radiation and variable viscosity effects on unsteady mixed convection flow in the stagnation region on a vertical surface embedded in a porous medium with surface heat flux", Far East journal of Mathematical sciences (FJMS), Volume 29, pp. 187 - 207.

[7] Hassanien, I.A., Ibrahim, F.S., Omer, Gh.M., (2004), "Unsteady free convection flow in the stagnation-point region of a rotating sphere embedded in a porous medium", Mechanics and Mechanical Engineering,Vol.7, No.2, pp. 89-98.

[8] Hassanien, I.A., Ibrahim, F.S., Omer, Gh.M., (2006), "Unsteady flow and heat transfer of a viscous fluid in the stagnation region of a three-dimensional body embedded in a porous medium", Journal of Porous Media,Vol.9,No. 4, pp. 357-372.

[9] Ingham D. B., (1985), "Flow past a suddenly heated vertical plate", Proceedings of the Royal Society of London, Series A, Mathematical and physical science, Vol. 402A, pp. 109-134.

[10] Kumari M., (1997), "Development of flow and heat transfer on a wedge with a magnetic field", Archives of Mechanics. Vol. 49, No.5, pp. 977-990.

[11] Nanbu K., (1971), "Unsteady Falkner Skan flow", Zeitschrift Fur Angewandte Mathematik und Physik ( ZAMP), Vol. 22, No. 6 , pp. 1167-1172.

[12] Nithiarasu, P., Setharamu, K. N., and Sundararajin, T., (1997),"Natural convection heat transfer in a fluid saturated variable porosity medium", Int. J. Heat Mass Transfer, (1981), vol. 40, pp. 3955-3967.

[13] Ozturk A. and Ece M. C., (1995), "Unsteady forced convection heat transfer from a translating and spinning body", ASME Journal of Energy Resources Technology, Vol. 117, No. 4, pp. 318-323.

[14] Pereyra V., PASVA3, (1978), "An adaptive finite difference Fortran program for first order non-linear boundary value problems", Lecture Note in Computer Science, vol. 76, Springer, Berlin.

[15] Pop I., Gorla R. S. and Rashidi M., (1992), "The effect of variable viscosity on flow and heat transfer to a continuous moving flat plate", International Journal of Engineering and science, vol. 30, No. 1, pp. 1-6.

[16] Ramachandra N., Chen T., and Armaly B. F., (1988), "Mixed convection in the stagnation flows adjacent to vertical surface", J. Heat Transfer vol. 110, pp. 173-177.

[17] Scshadri R., Srccshylan N. and Nath G., (2002), "Unsteady mixed convection flow in the stagnation region of a heated vertical plate due to impulsive motion", Int. J. Heat and Mass Transfer vol. 45 pp. 1345-1352.

[18] Smith S. H., (1957), "The impulsive motion of a wedge in a viscous fluid", Zeitschrift Fur Angewandte Mathematik und Physik (ZAMP) Vol. 18, No.4pp. 508-522.

[19] Sparrow E.M., Quack H. and Boerner J., (1970), "Local non-similarity boundary solutions, AIAA vol. 8, pp. 1936-1942.

[20] Vafai, K. and Tien, C.L., "Boundary and inertia effects on flow and mass transfer in porous media", Int. J. Heat Mass Transfer, (1981), vol. 24, pp. 492-484.

[21] Vafai, K., "Heat transfer in variable porosity media", J. Fluid Mech., (1984), vol. 147, pp. 233-259.

[22] Watkins C. B., (1975), "Heat transfer in the boundary layer over an impulsively started flat plate", J. Heat Transfer vol. 97, pp. 492-484.

[23] Williams J. C. and Rhyne T. H., (1980), "Boundary layer development on a wedge impulsively set into motion", SIAM J. Appl. Math. Vol. 38, pp. 215-224. 


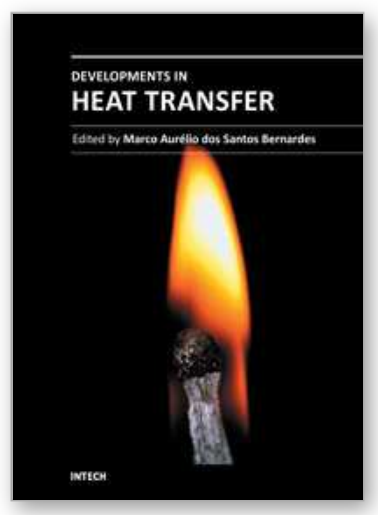

\author{
Developments in Heat Transfer \\ Edited by Dr. Marco Aurelio Dos Santos Bernardes
}

ISBN 978-953-307-569-3

Hard cover, 688 pages

Publisher InTech

Published online 15, September, 2011

Published in print edition September, 2011

This book comprises heat transfer fundamental concepts and modes (specifically conduction, convection and radiation), bioheat, entransy theory development, micro heat transfer, high temperature applications, turbulent shear flows, mass transfer, heat pipes, design optimization, medical therapies, fiber-optics, heat transfer in surfactant solutions, landmine detection, heat exchangers, radiant floor, packed bed thermal storage systems, inverse space marching method, heat transfer in short slot ducts, freezing an drying mechanisms, variable property effects in heat transfer, heat transfer in electronics and process industries, fission-track thermochronology, combustion, heat transfer in liquid metal flows, human comfort in underground mining, heat transfer on electrical discharge machining and mixing convection. The experimental and theoretical investigations, assessment and enhancement techniques illustrated here aspire to be useful for many researchers, scientists, engineers and graduate students.

\title{
How to reference
}

In order to correctly reference this scholarly work, feel free to copy and paste the following:

S. M. Alharbi and I. A. Hassanien (2011). Unsteady Mixed Convection Flow in the Stagnation Region of a Heated Vertical Plate Embedded in a Variable Porosity Medium with Thermal Dispersion Effects, Developments in Heat Transfer, Dr. Marco Aurelio Dos Santos Bernardes (Ed.), ISBN: 978-953-307-569-3, InTech, Available from: http://www.intechopen.com/books/developments-in-heat-transfer/unsteady-mixedconvection-flow-in-the-stagnation-region-of-a-heated-vertical-plate-embedded-in-a-var

\section{INTECH}

open science | open minds

\section{InTech Europe}

University Campus STeP Ri

Slavka Krautzeka 83/A

51000 Rijeka, Croatia

Phone: +385 (51) 770447

Fax: +385 (51) 686166

www.intechopen.com

\section{InTech China}

Unit 405, Office Block, Hotel Equatorial Shanghai

No.65, Yan An Road (West), Shanghai, 200040, China

中国上海市延安西路65号上海国际贵都大饭店办公楼 405 单元

Phone: +86-21-62489820

Fax: $+86-21-62489821$ 
(C) 2011 The Author(s). Licensee IntechOpen. This chapter is distributed under the terms of the Creative Commons Attribution-NonCommercialShareAlike-3.0 License, which permits use, distribution and reproduction for non-commercial purposes, provided the original is properly cited and derivative works building on this content are distributed under the same license. 